\title{
Investigation of the Correlation between Belonging Needs of Students Attending University and Well-being*
}

\author{
Ömer Karaman*, Bilge Tarim \\ Department of Guidance and Counseling, Education Faculty, Ordu University, Ordu, Turkey
}

Copyright $\bigcirc 2018$ by authors, all rights reserved. Authors agree that this article remains permanently open access under the terms of the Creative Commons Attribution License 4.0 International License

\begin{abstract}
Belonging is one of the basic psychological needs dealt with by many conceptualists. In different contexts the need to belong may be met at different levels. In this study the affiliation of 276 university students (178 females $64.5 \%$, 98 males $35.5 \%$ ) to their university was dealt with. The aim of this study is to investigate the correlation between the students' belonging to the university and well-being levels. Students in the research group were aged from 18 to 26 years, with mean age of 20.7 and standard deviation of 1.53. The group included $111(40.2 \%)$ first year students, 95 (34.4\%) second year students, $46(16.7 \%)$ third year students and $24(8.7 \%)$ fourth year students. Of students, $16(5.8 \%)$ had poor economic status, 157 (56.9\%) had moderate, 94 (34.1\%) had good and $9(3.3 \%)$ had very good economic status. The data collection tools of the Belonging to the University Scale and PERMA Profiler were used along with a personal information form. Analysis in the research used the multiple regression analysis and correlation techniques. According to the analysis results, the belonging to the university subdimensions of identification, expectation and motivation had a low level and significant correlation with well-being and these three subdimensions explained $15 \%$ of well-being. Additionally, there were significant correlations determined between belonging to the university, well-being, identification, meaning and health variables. In conclusion, as the belonging to the university level increases, it is considered university students' well-being levels will increase.
\end{abstract}

Keywords Belonging to University, Well-being, Identification, Expectations, Motivation

\section{Introduction}

The fulfillment of needs is important for individuals to maintain a healthy life. Humans are social beings, and in addition to basic requirements must also fulfil psychological requirements. One of these is the need to belong.

Belonging is a basic requirement comprising the association of everyone with each other with a hierarchy involving physiological needs, safety, respect, self-actualization and esthetic needs, combining to create human motivation. An individual feels the absence of their partner, lover, friend or child and wishes to belong to groups or a family to fulfil this requirement [1]. If the need to belong is not fulfilled, individuals may feel the pain of loneliness, exclusion, rejection, lack of friendship and feeling uprooted. This need may occur when a common threat is present. To survive and for a healthy life, it is necessary to meet the need to belong [2]. The need to belong is stated as associating with others, being valued by others and valuing others [3].

According to Adler, who saw belonging as a basic need and motivation for humanity, people who belong have good functioning. Additionally, Adler considered that the need to belong was the basis of a well-developed social network related to the person feeling equal to their own people and others. There is a close association between peoples' feeling of belonging and their tendency to reach others. People with increased feeling of belonging are oriented towards other people, while orienting towards others increases a person's feeling of belonging [4]. Together with an individual's skills in forming relationships with others, they come into the world with the skill of belonging. No matter that this skill is inherent; the feeling of belonging may not be developed. However, according to Adler, the feeling of belonging may develop after learning by making choices appropriate to abilities and creativity $[4,5]$.

Belonging also comprises one of the five basic requirements as defined by Glasser along with survival, power or recognition, freedom and fun. Though this classification shows parallels with the hierarchy of needs, contrary to Maslow, each need has equal power [6]. According to Glasser, love and belonging is a basic requirement met by partners, friends, family, pets, plants or objects representing sharing and cooperation [7] Of these five needs, the one most clearly motivating human 
behavior is the need to belong [8]. As we need humans to fulfil our needs, belonging is the most basic need and appears to be the most difficult to fulfil [7].

The need to belong may trigger people's hopes about life and reproduction when they are alone. As individuals without social bonds may not fulfil the need to belong, they appear to have high rates of mental and physical disease [9] Adler stated that psychological discomfort is revealed by individuals not feeling they belong. Not fulfilling the feeling of belonging may simultaneously reduce a person's trust in themselves and others and cause a transition to defense [4]. This situation drags an individual into isolation, anxiety, depression or addiction [5].

It is thought that all humans have a need to belong; however, there are individuals proposing that people can be comfortable without close relationships $[4,10]$. Research in this context found that people with obsessive bonding had high need to belong, while people with dismissive bonding have low needs [11]. Carvallo and Gabriel (10) in their study revealed that those with dismissive bonding style felt the need for acceptance by others and belonging. Additionally, individuals with high need to belong may have an anxious bonding style [12]. The need to belong was also found to be related to perfectionism expected of themselves and others, shyness [11], reputation [13], self-talk, loneliness [14], mental health [15], social inhibition, internalizing problems [16], tendency to forgive, self-esteem [12], life satisfaction [14], narcissism [17] and well-being [18].

There are studies dealing with belonging in the context of school [19-22]. Belonging to school, defined as students' feeling acceptance, respect, support and inclusion in the social environment of school, has a significant effect on academic motivation, bonding and engagement. Warm, respectful, cooperative-based interactions feed the feeling of belonging and create an effective educational environment [23]. The need to belong to school among middle school students was identified to be affected more by the students' mental and physical conditions than their individual and family traits [24]. A study of school bonds among high school students concluded that for youths exposed to bad treatment, school bonding created by supportive relationships with adults in the school and participation in school clubs may be effective in reducing absenteeism and failure in school [25]. It was stated that the feeling of belonging to school among high school students may be closely associated with social exclusion [26]. Additionally, the expectations, teacher support and bonding to school of university students appears to be related to feelings of belonging to university [27]. Additionally, belonging to university appears to have a positive correlation with maternal, paternal and friend relationships, belonging to high school, perceived school competence, self-worth, social acceptance, friendship quality and tendency to work, while there is a negative correlation with internalizing and externalizing problems
$[28,29]$. Karaman [30] dealt with belonging to university with a three-factor structure of identification represented by being a part of the university, expectations represented by student's expectations from the university and motivation represented by motivation levels in university.

One of the great contributions to the literature of the positive psychology approach focusing on helping an individual to adapt best to life is the concept of well-being [31]. Well-being has been studied by many researchers [32-34]. Well-being does not mean an absence of mental discomfort, but is a concept focusing on finding the optimal level of functioning and personal growth by expressed experience [35].

There are two philosophical opinions expressing well-being. One of these emphasizes hedonism as pleasure or happiness, while the eudaimonic view emphasizes individuals fulfilling their potential [36]. The hedonistic view defends the idea that the individual's aim in life is to experience pleasure at the highest level, beyond purely physical pleasure it mentions subjective happiness involving all judgements of an individual about life. Within this framework subjective well-being representing happiness means that for satisfaction from life positive emotions should be greater while negative emotions are less [36]. The eudaimonic view sees individuals as skilled beings and that they will be happy by fulfilling their life potential to the highest levels and living in accordance with their true selves. Together with this view, psychological well-being is represented by six dimensions of autonomy, personal development, self-acceptance, life aims, mastery and positive relationships [37].

The authentic happiness theory combining the eudaimonic and hedonic viewpoints explains well-being with five dimensions; positive feelings, participation, meaning, positive relationships and success $[38,39]$. Positive feelings represent feelings like fulfillment, satisfaction, pride and serenity related to the past, present and future. One of the routes to well-being for a person is engagement. During participation in interesting and engaging activities involving flow like music, sport, games and religious ceremonies, a person does not notice how time passes and gives their full attention to the activity. Meaning involves a person binding to a more powerful or higher aim and creating positive social relationships in the pursuit of happiness. Positive feelings are represented by being loved, supported and valued by others. Finally, success is a concept that may be measured objectively or subjectively, and it is obtainable and maintainable. More than the other four dimensions of well-being, an individual may be motivated most by accomplishment, being sufficient and mastery [38-40].

According to the self-determination concept, belonging is one of the three universal psychological needs along with autonomy and competence and fulfilling these needs affects satisfaction [3, 41]. Baumeister and Leary [42] have proved that close and long-term social relations are 
important to meet the need for belonging and this situation supports the state of well-being. Also a high correlation has been found between the belonging need and goodness in the study of Steptoe and his colleagues on the heart patients [43]. Again, the results of the research on volunteer associations have shown that volunteers meet their needs for harmony, social support and belonging with their works and this contributes to goodness [44].

In another study, it has been determined that the satisfaction of belonging requirements and goodness influence the alleviation of depression severity together [45].

This study researched the correlation between the belonging needs of university students toward their university and well-being levels. In other words, it is assumed that students who fulfill their need to belong to the university of study will have increased well-being. Students with expectations about university participate in interesting activities offered by the university experiencing flow and fulfillment which will affect the student's well-being. Students who feel they are part of their university, in other words who identify with their university, will form positive relationships and give meaning to their student experiences which will increase well-being. At the same time, high motivation levels of students related to university will increase success and with it well-being.

The basic aim of the study is to reveal the correlation between the belonging to university status of university students with well-being. The study also assesses the correlations between the subdimensions of belonging to university of identification, expectation and motivation with the subdimensions of well-being represented by positive feelings, participation, meaning, positive relationships and success

\section{Materials and Methods}

\subsection{Research Pattern}

The study used a relational screening model with the aim of determining the correlations between belonging to the university and well-being, the subdimensions of belonging to the university of identification, expectation and motivation and the subdimensions of well-being of positive emotions, participation, meaning, positive relationships and success [46]. The dependent variable in the research was well-being, while the independent variable was belonging to the university.

\subsection{Research Group}

The research group comprised a total of 276 people, 178 females (64.5\%) and 98 males (35.5\%), aged from 18 to 26 years. The mean age in the group was 20.27 and standard deviation was 1.53 . The group included $111(40.2 \%)$ first year students, 95 (34.4\%) second year students, 46 (16.7\%) third year students and $24(8.7 \%)$ fourth year students. Of students, 16 (5.8\%) had poor economic status, 157 (56.9\%) had moderate, 94 (34.1\%) had good and $9(3.3 \%)$ had very good economic status. When creating the research group, appropriate sampling and maximum variability methods were used [46, 47]. Descriptive statistics for the research group are shown in Table 1. Data Collection Tools

The data collection tools in the research were the Belonging to the University Scale to determine students' state of belonging to the university, the PERMA profiler to determine well-being levels and a personal information form created by the researchers to obtain demographic data for the research.

Table 1. Descriptive Statistics of the research group

\begin{tabular}{|ccc|}
\hline & $\mathrm{n}$ & $\%$ \\
\hline Gender & $\mathbf{2 7 6}$ & $\mathbf{1 0 0}$ \\
\hline Female & 178 & 64,5 \\
Male & 98 & 35,5 \\
Year level & $\mathbf{2 7 6}$ & $\mathbf{1 0 0}$ \\
1st year & 111 & 40,2 \\
2nd year & 95 & 34,4 \\
3rd year & 46 & 16,7 \\
4th year & 24 & 8,7 \\
Perceived Socioeconomic Level & $\mathbf{2 7 6}$ & $\mathbf{1 0 0}$ \\
Bad & 16 & 5,8 \\
Moderate & 157 & 56,9 \\
Good & 94 & 34,1 \\
Very Good & 9 & 43162 \\
\hline
\end{tabular}

\subsubsection{Belonging to the University Scale (BUS)}

The Belonging to the University scale developed by Karaman [30] comprises 14 items and has a 3-factor construct. The subdimensions of the scale are identification, motivation and expectations. The scale was developed with a 5-point Likert type given points from 1 to 5. The total points that can be obtained from the scale vary from 14 to 70. High points obtained from the scale show that students have higher levels of belonging to their university. To test the reliability of the scale the internal consistency coefficient was 0,75 , with test-repeat test correlation coefficient of 0,88 . Reliability analysis completed within the scope of this research determined the internal consistency coefficients were 0,75 for the identification subdimension, 0,75 for the motivation subdimension and 0,66 for the expectation subdimension with total internal consistency coefficient determined as 0,86 and coefficients were deemed acceptable [48].

\subsubsection{PERMA Profiler}

Developed originally by Butler and Kern [40], the Turkish adaptation of the PERMA profiler was completed 
by Demirci, et al. [49]. The scale comprises 15 items and 8 filler items for a total of 23 items and has a 5-factor structure with points from $0-10$. The subdimensions of the scale are positive emotions, engagement, positive relationships, meaning and accomplishment. Each subdimension of the scale has 3 items. Six of the 8 filler items on the scale deal with two separate dimensions of health and negative emotions. Item 23 on the scale measures happiness, while item 12 measures loneliness. Points for each subdimension on the scale are calculated as the mean for the three items belonging to that dimension. The PERMA total points are calculated as the mean of the total points for the 15 items of the positive emotions, engagement, positive relationships, meaning and accomplishment along with the happiness (item 23) item. High points obtained on the scale show greater well-being. To test the reliability of the PERMA Turkish form, the internal consistency coefficient was determined as 0,91 with test-repeat test correlation coefficient of 0,83 . Reliability analysis completed within the scope of this research found internal consistency coefficients were 0,83 for positive emotions, 0,54 for engagement, 0,68 for positive relationships, 0,78 for meaning, 0,65 for accomplishment, 0,65 for negative emotions, 0,82 for health and total internal consistency coefficient was 0,91 and coefficients were deemed acceptable [48].

\subsubsection{Personal Information Form}

With the aim of obtaining other variables to be used in the study, the researchers created a personal information form. The form included demographic variables of gender, age, year level and perceived socioeconomic status.

\subsection{Data Collection and Analysis}

Before the data was collected, official permission was obtained from the university administration. The data were collected from students at each level from each department of the university in the direction of appropriate sampling and maximum diversity method. A brief explanation was given to the students about the research and it was applied to the volunteer students.

To reveal the differences and correlations in the research, the answers to two questions were investigated:

1) Do the subdimensions of belonging to the university of identification, motivation and expectation predict well-being?

2) Are there significant correlations between belonging to the university, well-being and the subdimensions of these two variables?

For the first problem the multiple regression technique was used to reveal to what extent the independent variables explained the dependent variable and the correlations between variables $[47,50]$. For the second problem the simple regression analysis technique was used, to determine to what extent the independent variable explained the dependent variable and the correlation between variables [50]. In this context, the dependent variable is well-being, while the independent variable is belonging to the university. Data were analyzed with the SPSS 20 program.

\section{Results}

\subsection{Descriptive Statistics}

Descriptive statistics related to the variables are given in Table 2.

Table 2. Descriptive Statistics of Variables

\begin{tabular}{|cccc|}
\hline & $\mathrm{n}$ & $\mathrm{X}$ & $\mathrm{SD}$ \\
\hline Year Level & $\mathbf{2 7 6}$ & & $\mathbf{0 , 9 5}$ \\
Perceived Socioeconomic Level & $\mathbf{2 7 6}$ & & $\mathbf{0 , 6 3}$ \\
Identification & 276 & 2,77 & 0,64 \\
Motivation & 276 & 3,04 & 0,84 \\
Expectations & 276 & 2,77 & 0,81 \\
Belonging to the University & $\mathbf{2 7 6}$ & $\mathbf{3 8 , 2 1}$ & $\mathbf{9 , 1 7}$ \\
(BUS) & 276 & 6,43 & 1,81 \\
Positive feelings & 276 & 6,88 & 1,52 \\
Engagement & 276 & 6,46 & 1,8 \\
Positive Relationships & 276 & 6,6 & 1,7 \\
Meaning & 276 & 6,65 & 1,45 \\
Accomplishment & 276 & 7,25 & 1,88 \\
Health & 276 & 4,93 & 1,76 \\
Negative relationships & $\mathbf{2 7 6}$ & $\mathbf{1 4 6 , 9 3}$ & $\mathbf{2 9 , 2 1}$ \\
Well-being & & &
\end{tabular}

\subsection{Results related to the First Problem}

The Pearson Moments Multiplication correlation, mean and standard deviation values related to the belonging to the university, well-being, belonging to university subdimension of identification and the well-being subdimensions of meaning and health are given in Table 3.

According to the correlation analysis results, there is a moderate-level, positive and significant correlation between belonging to the university and well-being $(r=0,41$, $\mathrm{p}<0,01 ; 99 \%$ CI $[0,26,0,55])$. Accordingly, it may be said that when students feel they belong to the university they will be happier. There were low-level, positive and significant correlations present between the belonging to the university subdimension of identification and the well-being subdimensions of meaning $(\mathrm{r}=0,30, \mathrm{p}<0,01$; $99 \%$ CI $[0,14,0,44])$ and health $(\mathrm{r}=0,20, \mathrm{p}<0,01 ; 99 \%$ CI $[0,25,0,55])[47,48]$. 
Table 3. Mean, standard deviation and Pearson Moments Multiplication Correlation results for variables

\begin{tabular}{|cccccc|}
\hline Variables & 1 & 2 & 3 & 4 & 5 \\
\hline BUS & 1 & & & & \\
Well-being & $0,41^{* *}$ & 1 & & & \\
Identification & $0,36^{* *}$ & $0,58^{* *}$ & 1 & & \\
Meaning & $0,34^{* *}$ & $0,80^{* *}$ & $0,30^{* *}$ & 1 & \\
Health & $0,15^{*}$ & $0,62^{* *}$ & $0,20^{* *}$ & $0,42^{* *}$ & 1 \\
Mean & 38,21 & 146,93 & 4,93 & 6,6 & 7,25 \\
SD & 9,17 & 29,21 & 1,76 & 1,7 & 1,88 \\
\hline
\end{tabular}

** $\mathrm{p}<0,01, * \mathrm{p}<0,05 ; \mathrm{N}=276$; SD: Standard Deviation; BUS: Belonging to the University Scale

\subsection{Results related to the Second Problem}

Simple regression analysis was performed to reveal the determinants of well-being. The low-level effect of belonging to the university on well-being is given in Table 4. According to the results, belonging to the university explains $17 \%$ of well-being $(\mathrm{F}(1,3947)=55,40, \mathrm{p}<0,001)$. The contribution of belonging to the university to the model was found to be significant $(\beta=0,41, \mathrm{p}<0,001 ; 99 \%$ CI $[0,26,0,55])$.

Table 4. Standard Simple Regression Analysis Results for prediction of Well-being

\begin{tabular}{|c|c|c|c|c|c|}
\hline Variables & B & SHB & B & t & p \\
\hline Stable & 97,02 & 6,89 & & 14,07 & 0,00 \\
\hline BUS & 1,30 & 0,14 & 0,41 & 7,44 & 0,00 \\
\hline
\end{tabular}

$\mathrm{R}=0,41, \mathrm{R}^{2}=0,17$; BUS: Belonging to the University Scale.

\section{Discussion}

In this study the need to belong to the university was dealt with which affects the true meaning of university experiences forming a large part of a young adult's life. In this context the need to belong to the university was determined as the independent variable and the effect of this requirement on students' well-being was identified. In this context the results obtained are discussed in light of the literature.

Eryllmaz [51] reached findings that satisfying needs increased well-being. This situation states that individuals meeting their requirements will have high levels of happiness. A study dealing with the variables of life satisfaction and need fulfillment, one of the concepts explaining the concept of well-being, similarly concluded that need fulfillment has a direct effect on life satisfaction [52]. There are also studies in the literature dealing with the need to belong and the well-being variable. The results of a study dealing with the need to belong and well-being of teacher candidates found the requirement to belong was associated with well-being [53]. A study of individuals with depression found the link between belonging to social interactions and well-being of individuals with more depressive symptoms was higher compared to individuals without depression [54]. A qualitative study stated there were many obstacles to adults with autism feeling they belong in the social area and these obstacles harmed well-being [55]. A qualitative study of youngsters dealt with the concept of belonging affecting well-being under the theme of being a group member [56]. Another study found that refugees living in a society with common experiences developed the feeling of belonging and increased well-being [57]. These studies performed in a variety of groups show that the need to belong has a significant effect on well-being.

The study by Karaman $[19,30]$ dealt with belonging in specific form in terms of bonds to the university. An individual's need to belong may not be simultaneously met in all contexts at the same level. For example, an individual who feels they belong to a family environment may not fulfil their need to belong in work life. Similarly, there are studies which limit an individual's need to belong to a context like a neighborhood, family or school and investigate the correlation with well-being $[58,59]$. There was a moderate level, positive and significant correlation found between belonging to the university and well-being in the research. Additionally, belonging to the university significantly predicted well-being. According to this result, $17 \%$ of well-being of students comprised the fulfillment of their need to belong to the university. There is no study found dealing with belonging to the university and well-being together. However, similar to this study, there is a longitudinal study dealing with belonging to school status and subjective well-being of students aged from 9-14 years. According to the research based on a structural equivalence model, there is a two-way correlation between belonging to school and subjective well-being [60]. In conclusion, students who identify with, have their expectations met and have high motivation in university will increase their positive feelings, the positive relationships they form, meaning given to life, participation in activities involving flow and feelings of accomplishment.

Finally, the research found low-level, positive and significant correlations between the subdimension of belonging to the university of identification and the well-being subdimensions of meaning and health. The correlation between identification and meaning was effective in conceptualizing the research and is an expected result. According to these findings, a student who feels they are part of the university will give meaning to the experience and be happy. The association between identification and health was outside of our expectations. According to this result, a student describing themselves as healthy may be said to feel they are part of their university.

\section{Conclusions}

The study concluded that fulfillment of a need to belong to the university was effective on well-being among 
students. There are very few studies in the literature dealing with the concept of belonging in the university context [27-29]. Additionally, there is no study assessing the concept of belonging to the university in terms of student well-being. Though this study fills this gap in the literature, there is a need to perform similar studies to support the present research.

Currently satisfaction of students is important in terms of ensuring they complete their aims and continue in the competitive environment of university. In this way it will be beneficial for universities to create environments where identification may form, expectations are met and motivation increases to increase student well-being. From another viewpoint, according to the data obtained in the study the necessity to create policies related to meeting students' belonging requirements in universities may be proposed. For example, within the framework of these policies universities should support the creation of student clubs allowing the opportunity for activities where students may experience flow and should organize interesting social activities.

\section{REFERENCES}

[1] Maslow AH. A theory of human motivation. Psychological Review, 50(4): 370-396, 1943.

[2] Maslow AH. A theory of human motivation. In, Motivation and personality, 2. Edition, ABD: Harper \& Row, 1970.

[3] Ryan RM, Deci EL. Self-determination theory and the facilitation of intrinsic motivation, social development, and well-being. American Psychologist, 55(1): 68-78, 2000.

[4] Dreikurs Ferguson E. Adler's innovative contributions regarding the need to belong. The Journal of Individual Psychology, 66(1): 1-7, 2010.

[5] Shifron R. Adler's need to belong as the key for mental health. The Journal of Individual Psychology, 66(1), 10-29: 2010.

[6] Litwack L. Basic needs - a retrospective. International Journal of Reality Therapy, 26(2): 28-30. 2007.

[7] Corey G. Reality Therapy. In T. Ergene (Ed.) Psychological counseling, psychotherapy theory and practices 7. Edition, Mentis Publication İstanbul, 2008.

[8] Wubbolding RE. The power of belonging. International Journal of Reality Therapy, 24(2): 43-44. 2005.

[9] Baumeister RF, Brewer LE, Tice DM, Twenge JM. Thwarting the need to belong: understanding the interpersonal and inner effects of social exclusion. Social and Personality Psychology Compass, 1(1): 506-520, 2007.

[10] Carvallo M, Gabriel S. No man is an island: the need to belong and dismissing avoidant attachment style. Personality and Social Psychology Bulletin, 32(5), 697-09, 2006. doi: $10.1177 / 0146167205285451$
[11] Chen C, Hewitt PL, Flett GL. (2015). Preoccupied attachment, need to belong, shame, and interpersonal perfectionism: an investigation of the perfectionism social disconnection model. Personality and Individual Differences, 76: 177-182, 2015.

[12] Barnes CD, Carvallo M, Brown RP, Osterman L. Forgiveness and the need to belong. Personality and Social Psychology Bulletin, 36(9): 1148 -1160, 2010.

[13] Greenwood D, Long CR, Cin SD. Fame and the social self: the need to belong, narcissism, and relatedness predict the appeal of fame. Personality and Individual Differences, 55: 490-495, 2013.

[14] Mellor D, Stokes M, Firth L. Hayashi Y, Cummins R. Need for belonging, relationship satisfaction, loneliness, and life satisfaction. Personality and Individual Differences, 45: 213-218, 2008.

[15] Reichl C, Schneider JF, Spinath FM. Relation of self-talk frequency to loneliness, need to belong, and health in German adults. Personality and Individual Differences, 54: 241-245, 2013.

[16] Moor EL, Denolleta J, Laceullea OM. Social inhibition, sense of belonging and vulnerability to internalizing problems. Journal of Affective Disorders, 225: 207-213, 2018.

[17] Dumas TM. Maxwell-Smith M, Davis JP, Giulietti PA Lying or longing for likes? Narcissism, peer belonging, loneliness and normative versus deceptive like seeking on Instagram in emerging adulthood. Computers in Human Behavior, 71: 1-10. 2017.

[18] Cramm JM, Nieboer AP. Social cohesion and belonging predict the well-being of community-dwelling older people. BMC Geriatrics, 15(30): 1-10, 2015.

[19] Karaman Ö, Cirak Y. The Belongıng to the Unıversity Scale. Acta Didactica Napocensia. 10(2):1-20, 2017.

[20] Kustatscher M. The emotional geographies of belonging: children's intersectional identities in primary school. Children's Geographies, 15(1), 65-79, 2017.

[21] Layous K, Davis EM, Garcia J, Purdie-Vaughns V, Cook JE, Cohen GL. Feeling left out, but affirmed: protecting against the negative effects of low belonging in college. Journal of Experimental Social Psychology, 69: 227-231, 2017.

[22] Kuo FW, Yang SC. The moderating effect of the need to belong and classroom composition on belongingness seeking of minority adolescents. Journal of Adolescence, 61: 22-30, 2017.

[23] Freeman TM, Anderman LH, Jensen JM. Sense of belonging in college freshmen at the classroom and campus levels. The Journal of Experimental Education, 75(3): 203220. 2007

[24] Ma X. Sense of belonging to school: can schools make a difference? The Journal of Educational Research, 96(6): 340-349, 2003.

[25] Lemkin A, Kistin CJ, Cabral HJ, Aschengrau A, Bair-Merritt M. School connectedness and high school graduation among maltreated youth. Child Abuse \& Neglect, 75: 130-138, 2018. 
[26] Ham SH, Yang KE, Cha YK. Immigrant integration policy for future generations? A cross-national multilevel analysis of immigrant-background adolescents' sense of belonging at school. International Journal of Intercultural Relations, 60: 40-50, 2017.

[27] Goodenow C. Classroom belonging among early adolescent students. Journal of Early Adolescence, 13(1): 21-43, 1993.

[28] Pittman LD, Richmond A. Academic and psychological functioning in late adolescence: the importance of school belonging. The Journal of Experimental Education, 75(4) 270-290, 2007.

[29] Pittman LD, Richmond A. University belonging, friendship quality, and psychological adjustment during the transition to college. The Journal of Experimental Education, 76(4): 343-361, 2008.

[30] Karaman O. Observing the belonging of the requirements of the students that they are attending. (Doctoral dissertation thesis). Retrieved from YÖK Tez Merkezi (333816), (2013).

[31] Eryılmaz A. Using of positive psychology on psychological counseling and guidance context on character strength and preventive services. The Journal of Happiness \& Well-Being, 1(1): 1-22, 2013.

[32] Marinoa C, Ginia G, Vienoa A, Spada MM. The associations between problematic Facebook use, psychological distress and well-being among adolescents and young adults: A systematic review and meta-analysis. Journal of Affective Disorders, 226: 274-281, 2018.

[33] Cikrikci O. effect of internet use on well-being: Meta-analysis. Computers in Human Behavior, 65: 560-566, 2016.

[34] Yalçin I. Relationship between well-being and social support: A meta-analysis of studies conducted in Turkey. Turkish Journal of Psychiatry, 26(1): 21-32, 2015.

[35] Seligman MEP, Csikszentmihalyi M. Positive psychology. American Psychologist, 55(1): 5-14, 2000.

[36] Ryan RM, Deci EL. On happiness and human potentials: A review of research on hedonic and eudaimonic well-being. Annual Review Psychology, 52: 141-166, 2001.

[37] Ryff CD, Singer B. The contours of positive human health. Psychological Inquiry Copyright, 9(1): 1-28, 1998.

[38] Schueller SM, Seligman MEP. Pursuit of pleasure, engagement, and meaning: Relationships to subjective and objective measures of well-being. The Journal of Positive Psychology, 5(4): 253-263, 2010.

[39] Seligman M. Flourish: Positive psychology and positive interventions. Michigan: The University of Michigan, 2010.

[40] Butler J, Kern ML. The PERMA-Profiler: A brief multidimensional measure of flourishing. International Journal of Wellbeing, 6(3): 1-48, 2016.

[41] Deci EL, Ryan RM. Self-determination theory: a macro theory of human motivation, development, and health. Canadian Psychology, 49(3): 182-185, 2008.

[42] Baumeister RF, Leary MR. The need to belong: Desire for interpersonal attachments as a fundamental human motivation. Psychological Bulletin, 117: 497-529, 1995.

[43] Stefanone M A, Jang CY. Writing for friends and family: The interpersonal nature of blogs. Journal of Computer-Mediated Communication, 13(1): 7, 2007.

[44] Thoits PA, Hewitt LN. Volunteer Work and Well-Being. Journal of Health and Social Behavior. 42: 115-131, 2001.

[45] Steger MF, Kashdan TB. Depression and Everyday Social Activity, Belonging, and Well-Being. J Couns Psychol. 56(2): 289-300, 2009. doi: 10.1037/a0015416

[46] Fraenkel JR, Wallen NE. How to design and evaluate research in education: McGraw-Hill Higher Education 7. Edition, New York, 2009.

[47] Cohen L Manion L, Morrison K. Sampling. In, Research methods in education. 6. Edition, Routledge, New York. 2007.

[48] Field A. Exploratory factor analysis. in, Discovering statistics using SPSS. 3. Edition, Sage Publications, UK, 2013.

[49] Demirci I, Ekşi H, Dinçer D, Kardas S. Five-dimensional model of well-being: The validity and reliability of Turkish version of PERMA-Profiler. The Journal of Happiness and Well-Being, 5(1): 60-77, 2017.

[50] Tabachnick BG, Fidell LS. Multiple regressions. In, Using multivariate statistics. 5. Edition, Pearson Education. Boston, 2007.

[51] Eryılmaz A. A model for subjective well-being in adolescence: need satisfaction and reasons for living. Social Indicators Research, 107: 561-574, 2012.

[52] Cihangir-Çankaya Z. Support for autonomy, satisfying basic psychological needs and subjective well-being: Self-determination theory. Türk Psikolojik Danışma ve Rehberlik Dergisi, 4(31): 23-31, 2009.

[53] Cihangir-Çankaya Z. Satisfaction and well-being of basic psychological needs inteacher candidates. Türk Eğitim Bilimleri Dergisi, 7(3): 691-711, 2009.

[54] Steger MF, Kashdan TB. Depression and everyday social activity, belonging, and well-being. Journal of Counseling Psychology, 56(2): 289-300, 2009.

[55] Milton D, Sims T. How is a sense of well-being and belonging constructed in the accounts of autistic adults? Disability \& Society, 31(4): 520-534, 2016.

[56] Montague AC, Eiroa-Orosa FJ. In it together: Exploring how belonging to a youth activist group enhances well-being. Journal of Community Psychology, 46: 23-43, 2018.

[57] Burchett N, Matheson R. The need for belonging: The impact of restrictions on working on the well - being of an asylum seeker. Journal of Occupational Science, 17(2): 85-91, 2010.

[58] Young AF, Russell A, Powers RF. The sense of belonging to a neighbourhood: Can it be measured and is it related to health and well-being in older women? Social Science \& Medicine, 59, 2627-2637, 2004. 
[59] Hudson KD. Toward a conceptual framework for understanding community belonging and well-being: Insights from a queer-mixed perspective. Journal of Community Practice, 23(1): 27-50, 2015.
[60] Tian L, Zhang L, Huebner ES, Zheng X, Liu W. The longitudinal relationship between school belonging and subjective well-being in school among elementary school students. Applied Research Quality Life, 11: 1269-1285, 2016.

\footnotetext{
* This research was submitted as an oral presentation to Cyprus. 3. Cyprus International Congress of Education Research
} 